\title{
EFFECTS OF ACTIVATED BRACKISH WATER IRRIGATION ON THE GROWTH AND WATER USE EFFICIENCY OF MATURE FRAGRANT PEAR (PYRUS PYRIFOLIA L.)
}

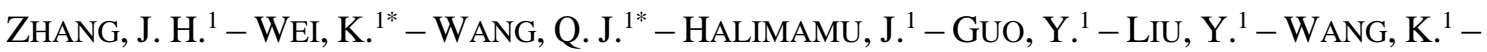 \\ CAO, L. ${ }^{2}$ \\ ${ }^{1}$ State Key Laboratory of Eco-hydraulics in Northwest Arid Region of China, Xi'an University \\ of Technology, Xi'an 710048, China \\ ${ }^{2}$ Shaanxi Fengxi Xincheng Investment Development Co., Ltd, Xi'an 710048, China \\ *Corresponding authors \\ e-mail: 18291869766@163.com,wquanjiu@163.com
}

(Received $9^{\text {th }}$ Aug 2021; accepted $23^{\text {rd }}$ Nov 2021)

\begin{abstract}
Understanding the effect and mechanism of activated brackish water irrigation on fruit tree growth is of great significance to improve the utilization efficiency of brackish water in Xinjiang, China. In this study, Korla fragrant pear (Pyrus pyrifolia $\mathrm{L}$.) was taken as the research object, and a two-year field irrigation experiment was carried out using brackish water (B), magnetized brackish water (MB) and ionized brackish water (IB) to study the effects of activated brackish water on the growth of new shoots, fruit shape, yield and quality, and water use efficiency of mature fragrant pear. The results showed that the rhizosphere soil water content increased somewhat under the activated brackish water irrigation. Compared to treatment B, the average soil water content under MB and IB irrigation increased by $13.07 \%-14.90 \%$ and $28.15 \%-28.55 \%$, respectively. In addition, the activated brackish water irrigation could effectively promote the growth and fruit development of fragrant pear trees. Compared with treatment $\mathrm{B}$, the maximum new shoot lengths increased by $17.87 \%-28.33$ and $48.79 \%-51.12 \%$, the fruit shape index increased by $9.62 \%-11.68 \%$ and $9.58 \%-10.66 \%$, respectively, the volume of fragrant pear increased by $8.96 \%-11.96 \%$ and $11.89 \%-15.54 \%$, respectively, the yield of fragrant pear increased by $11.20 \%-22.22 \%$ and $12.47 \%-25.08 \%$, respectively, and water use efficiency increased by $12.97 \%-25.24 \%$ and $14.15 \%-26.21 \%$, respectively. Furthermore, the single fruit weight and soluble solid content of fragrant pear significantly increased $(P<0.05)$, while the hardness and total acid content significantly decreased $(P<0.05)$. In conclusion, activated brackish water irrigation can effectively improve the yield and water use efficiency of fragrant pear, and ameliorate the shape and quality of fragrant pear fruit, alleviate the negative effects of brackish water.
\end{abstract}

Keywords: magnetized brackish water, ionized brackish water, fragrant pear, yield and quality

\section{Introduction}

Fragrant pear (Pyrus pyrifolia L.) is well-known inside and outside of China for its thin skin, thin meat, crisp and sweet juice and strong flavor (Niu et al., 2019). It has become one of the important high-earning export agricultural products in southern Xinjiang, China (Chen et al., 2020a). However, due to the large water consumption of fragrant pear and the extreme shortage of fresh water resources in Xinjiang, the sustainable development of forest and fruit industry in this area is seriously restricted ( $\mathrm{Li}$ et al., 2020b). The development and utilization of brackish water resources has become an adaptation strategy for drought resistance and yield increase in fruit tree cultivation in freshwater deficient areas (Han et al., 2019). However, there are salt ions in the brackish water. During irrigation, the water enters the soil, causing the accumulation of salt, resulting in the deterioration of the environment in the rhizosphere of fruit trees (Yuan et al., 2019), hindering the absorption of water and nutrients by the roots of fruit trees, thus 
reducing their productivity (Chen et al., 2018). Therefore, the continuous search for new technologies to improve the quality of brackish water has become a hot topic.

Activated water treatment technology mainly includes magnetized and ionized water treatment methods (Mu et al., 2019). After activation treatment, the physical and chemical properties of water change, the surface tension decreases, the viscosity and half peak width of 17O-NMR increase, and the associated water molecules decompose (Al-Bayar et al., 2020). When the activated brackish water enters the soil through irrigation, the proportion of soil exchangeable sodium ions decreases, and the substitution amount of calcium ions and magnesium ions increases, which changes the exchange characteristics and ion composition of soil base ions (Hamza, 2019), so as to ameliorate soil physical and chemical properties, improve the availability of soil nutrients, provide more ionic nutrients for crop growth, and promote the growth and development of crops (AbdelKader et al., 2020). Wang et al. (2021) showed that activated water irrigation could improve wheat root activity, improve root configuration, enhance leaf chlorophyll content and improve wheat yield. Turker et al. (2007) applied a stable magnetic field perpendicular to the gravity field of sunflower and found that both chlorophyll a and chlorophyll b of sunflower increased. Maheshwari and Grewal (2009) found that magnetized water improved the growth and physiological indexes of crops, such as the SPDA value of crop leaves, leaf area index and relative water content of plant leaves. Zhou et al. (2021) pointed out that the cotton yield under irrigation with $300 \mathrm{mT}$ magnetized water increased by $28.8 \%-31.69 \%$, and the water use efficiency increased by $27.4 \%-42.8 \%$. Surendran et al. (2016) believed that when the water flowed through the magnetic field, the positive and negative ions in the water were forced to separate. After entering the soil, the nutrient ions were easier to move, and the water molecules were easier to adhere to the soil pores and. It played a role in maintaining the water in the root zone of crops and promoting the growth of peas. Zhao et al. (2021) pointed that the yield of wheat irrigated with magnetized water and ionized water increased by $10.1 \%$ and $13.9 \%$, respectively, and the water use efficiency increased by $8.8 \%$ and $7.9 \%$, respectively.

At present, there has been extensive research on the activated brackish water irrigation of grain and economic crops, but there is little research on the activated water irrigation of fruit trees. Korla fragrant pear, as a unique variety in China, the impact of activated brackish water irrigation on the growth of fragrant pear fruit trees has not been reported publicly. Therefore, taking the mature fragrant pear fruit trees as the research object, through a two-years of field experiment, this paper analyzed the effects of activated brackish water on the growth, fruit shape, quality, yield and water use efficiency of fragrant pear trees, so as to provide a theoretical basis for the application of activated brackish water in fruit tree irrigation.

\section{Materials and methods}

\section{Experimental site description}

From 2018 to 2019 , the experimental study was carried out in a pear garden $\left(41^{\circ} 45^{\prime} \mathrm{N}\right.$, $86^{\circ} 10^{\prime} \mathrm{E}, 901 \mathrm{~m}$ a.s.1.) of water conservancy Research Institute of Tarim River Basin Authority, Korla City, Xinjiang, China. Located in the hinterland of the Eurasian continent, the experimental site is a typical temperate continental arid climate area, with an average annual temperature of $11.6^{\circ} \mathrm{C}$. The average annual precipitation is $58.6 \mathrm{~mm}$, the average annual evaporation is $2257.2 \mathrm{~mm}$, the frost free period is $226 \mathrm{~d}$, and the 
average annual sunshine hours is $2769.8 \mathrm{~h}$ (Wang et al., 2019b). The meteorological elements during the growth period of fragrant pear in 2018 and 2019 were shown in Fig. 1. The cumulative reference crop evapotranspiration $\left(E T_{0}\right)$ during the growth period of fragrant pear in 2018 is $1050 \mathrm{~mm}$, and the cumulative rainfall $(R)$ was $60 \mathrm{~mm}$. In 2019 , $\mathrm{ET}_{0}$ during the growth period of fragrant pear was $1025.8 \mathrm{~mm}$, and the cumulative rainfall $(R)$ was $42.9 \mathrm{~mm}$. Before the test, the basic physical and chemical properties of the soil in the $0-100 \mathrm{~cm}$ soil layer of the test site were measured. According to the soil texture classification of the U.S. Department of agriculture, the soil in the test area is sandy loam (50.2\% sand, $46.0 \%$ silt and $3.8 \%$ clay), with an average unit weight of $1.56 \mathrm{~g} \cdot \mathrm{cm}^{-3}$, a saturated volume water content of $0.43 \mathrm{~cm}^{3} \cdot \mathrm{cm}^{-3}$, a field water capacity of $0.25 \mathrm{~cm}^{3} \mathrm{~cm}^{-3}$, a wilting coefficient of $0.05 \mathrm{~cm}^{3} \cdot \mathrm{cm}^{-3}$, a pH value of 7.8 , a total nitrogen content of $0.84 \mathrm{~g} \cdot \mathrm{kg}^{-1}$ and an organic matter content of $13.24 \mathrm{~g} \cdot \mathrm{kg}^{-1}$ (Chen et al., 2020b). The content of alkali hydrolyzable nitrogen is $57.46 \mathrm{mg} \cdot \mathrm{kg}^{-1}$, the content of available phosphorus is $9.85 \mathrm{mg} \mathrm{kg}{ }^{-1}$, and the content of available potassium is $136.52 \mathrm{mg} \cdot \mathrm{kg}^{-1}$ (Li et al., 2019). From 2018 to 2019, the average buried depth of underground level is $6.5 \mathrm{~m}$. The brackish water comes from underground well water, and its salinity is $1.83-2.74 \mathrm{~g} \cdot \mathrm{L}^{-1}$. Fig. 1 showed the main meteorological factors during the growth period of fragrant pear.
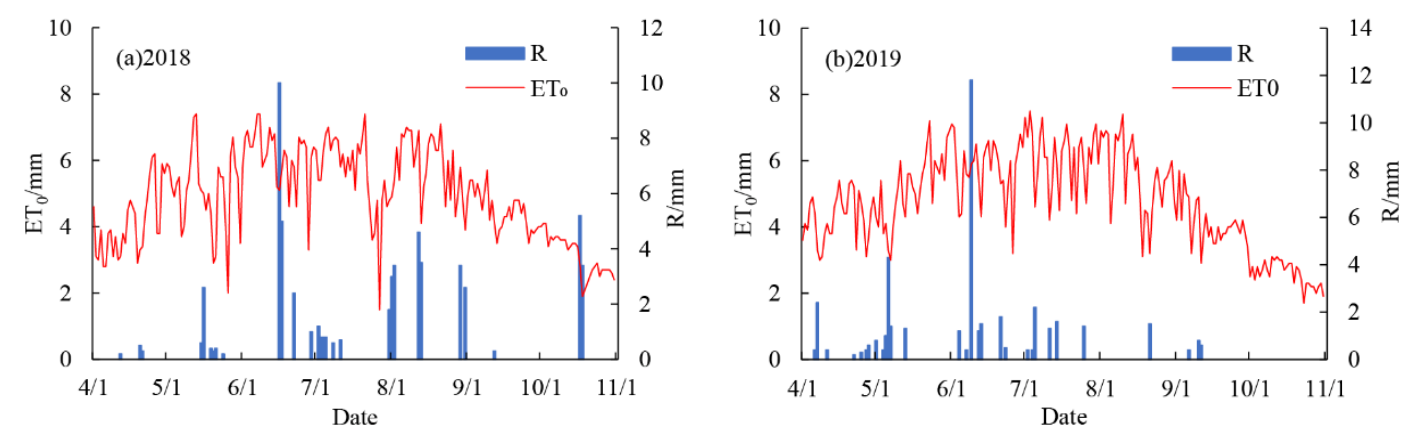

Figure 1. Main meteorological elements in growth period of fragrant pear. ET0 and $R$ represent the reference crop evapotranspiration and rainfall, respectively

\section{Magnetizer and magnetized water device}

The test started in early April and ended in mid-September every year. The tested materials were 15-year-old fragrant pear trees with a row spacing of $4 \mathrm{~m} \times 6 \mathrm{~m}$ $\left(417\right.$ trees $\left.\cdot \mathrm{hm}^{-2}\right) .3$ rows of fragrant pear trees with similar tree shape were selected, and divided into 9 communities. Each community was $12 \mathrm{~m}$ long and $6 \mathrm{~m}$ wide, including 5 fragrant pear trees. Taking different irrigation water treatments as influencing factors, three groups of treatments were set up, namely brackish water (B), magnetized brackish water (MB) and ionized brackish water (IB). Each treatment controlled the irrigation of 5 fragrant pear trees, repeated for 3 times and arranged randomly. Both the magnetized water processor and the ionized water processor were installed on the irrigation water diversion pipeline. The magnetized water processor adopted the pipeline magnetizer (XS300) with a magnetization of $300 \mathrm{mT}$ produced by Urumqi Water-saving Equipment Research and Development Center, Xinjiang, China. The ionized water processor (W600DELF) is produced by Korea Yameihua (Beijing) environmental technology Development Co., Ltd, China. According to the research of Wang et al. (2016), the technical parameters of the equipment were adjusted and controlled. The irrigation method was small tube outflow. $4 \mathrm{~mm}$ capillary was used to arrange 4 small tubes around 
the fragrant pear tree, and the small tube flow was $8 \mathrm{~L} \cdot \mathrm{h}^{-1}$. The irrigation quota was $5625 \mathrm{~m}^{3} \cdot \mathrm{hm}^{-2}$. Irrigation had been started since April 22, and the irrigation cycle was 10 days. A total of 15 times of irrigation had been carried out during the growth period, and the irrigation quota was $375 \mathrm{~m}^{3} \cdot \mathrm{hm}^{-2}$. The fertilization method was ditch application. During the growth period, $652 \mathrm{~kg} \cdot \mathrm{hm}^{-2}$ urea (containing $46 \% \mathrm{~N}$ ), $543 \mathrm{~kg} \cdot \mathrm{hm}^{-2}$ heavy superphosphate (containing $46 \% \mathrm{P}_{2} \mathrm{O}_{5}$ ) and $118 \mathrm{~kg} \cdot \mathrm{hm}^{-2}$ potassium sulfate (containing $51 \% \mathrm{~K}_{2} \mathrm{O}$ ) were applied. Other field management of each treatment group was consistent during the experiment. The old bark of fragrant pear fruit trees should be pruned and scraped before the end of February every year, meanwhile, the orchard should be clean. The chemicals should be sprayed before budding to reduce the base number of diseases and pests. When applying fertilizer, the root with a diameter of $0.5 \mathrm{~cm}$ should be careful not to hurt.

\section{Determination index and method}

\section{Soil water content}

PR2 soil water monitoring system (Davis instruments, California, USA) was adopted to determine the soil water content. Three trees with similar growth and healthy were randomly selected for each treatment. A PR2 pipe with a depth of $100 \mathrm{~cm}$ was buried at $50 \mathrm{~cm}$ and $100 \mathrm{~cm}$ in four directions along the East, West, North, South of each tree. There were 8 water monitoring points for each tree and 24 water monitoring points for each treatment. The soil water content was measured every 20 days at the depths of 10 , 20, 30, 40, 60 and $100 \mathrm{~cm}$, respectively. The soil moisture content determined by PR2 was calibrated according to the regression equation given by Liang et al. (2019).

\section{Shoot length}

According to the actual growth status of fragrant pear trees, 3 fragrant pear trees with uniform growth were selected for each treatment. During the germination period of fragrant pear trees, 4 new shoots with strong growth were randomly selected from the East, West, North and south directions around the crown as markers, and the length and diameter of new shoots were measured with steel tape and vernier caliper. They were measured every 7 days for 6 consecutive cycles.

\section{Fruit shape, yield and quality}

The yield of fragrant pear was measured in the first ten days of October every year. Three fragrant pear trees were randomly selected for each treatment, and the total number of fruits produced by each fragrant pear tree was accurately counted. 10 fragrant pear fruits are randomly picked on each fragrant pear tree. The longitudinal diameter $\left(D_{Z}, \mathrm{~mm}\right)$ and transverse diameter $\left(D_{H}, \mathrm{~mm}\right)$ were measured with vernier caliper, and the fruit shape index (Wang et al., 2020) $\left(S I=D_{Z} / D_{H}\right)$ and volume (Wu et al., 2012) $\left(V=0.002 D_{Z}{ }^{1.864}\right.$ $\left.D_{H}{ }^{0.803}, \mathrm{~cm}^{3}\right)$ were calculated. The single fruit weight of fragrant pear was measured with an electronic scale with an accuracy of $0.01 \mathrm{~g}$. The product of the single fruit weight and the total number of fruits was taken as the average yield per plant, and the total yield was obtained by area conversion based on the yield per plant. Two samples were selected from four directions of each fragrant pear tree, East, West, North and South, a total of 8 samples were selected to determine the fruit quality. The fruit hardness was determined by GY-2 fruit hardness tester (Vetus Instruments, USA), the soluble solid content was determined by WYT-4 handheld sugar meter (Guangzhou Mingrui Co., Ltd, China), the total acid 
content was determined by $\mathrm{NaOH}$ titration, and the vitamin $\mathrm{C}$ content was determined by dichloroindophenol titration.

\section{Meteorological data}

The Vantage Pro2-6152c meteorological station produced by Davis company of the United States was used to monitor the meteorological data such as maximum temperature, minimum temperature, sunshine time, $2 \mathrm{~m}$ wind speed, air humidity and rainfall during the growth period of fragrant pear.

\section{Calculation of water consumption and water use efficiency}

The water consumption in the growth period of fragrant pear fruit trees is calculated by water balance:

$$
E T=S W C+I+R+U-D-R_{0}
$$

where, ET represents the water consumption of fragrant pear tree $(\mathrm{mm}) . S W C$ represents the water storage in the main root zone of fragrant pear fruit tree $(\mathrm{mm})$. $I$ represents the amount of irrigation, $\mathrm{mm} . R$ represents the rainfall $(\mathrm{mm}) . U$ represents the recharge of groundwater $(\mathrm{mm}) . D$ represents the deep leakage $(\mathrm{mm}) . R_{0}$ is the surface runoff $(\mathrm{mm})$. Since the buried depth of groundwater is greater than $6 \mathrm{~m}, U$ could be ignored. In this test, small pipe outflow is adopted, the irrigation quota is small, there will be no leakage, so $D$ can be ignored. The irrigation quota is small, there will be no surface runoff, so $R_{0}$ can be ignored;

Since $U, D$ and $R_{0}$ are negligible, Eq. (1) can be simplified as:

$$
E T=S W C+I+R
$$

The water storage in the main root zone of fragrant pear can be calculated according to the measured soil water content data:

$$
S W C=1000 H\left(\theta_{t_{2}}-\theta_{t_{1}}\right)
$$

where, $H$ represents the depth of main root zone of fragrant pear $(\mathrm{m}) . \theta_{t 1}, \theta_{t 2}$ represent the average water content of soil at the depth of $0-100 \mathrm{~cm}$ in the main root zone at $\mathrm{t}_{1}$ and $\mathrm{t}_{2}$.

The water use efficiency (WUE) of fragrant pear fruit trees can be expressed as:

$$
W U E=100 Y / E T
$$

where, WUE represents the water use efficiency of fragrant pear trees $\left(\mathrm{kg} \cdot \mathrm{m}^{-3}\right) . Y$ represents the yield of fragrant pear $\left(\mathrm{t} \cdot \mathrm{hm}^{-2}\right)$.

\section{Data processing and analysis}

The data were recorded in Excel 2019 and analyzed using SPSS 22.0 software (IBM Corp. USA). Duncan method was used for significance test and analysis of variance $(P<0.05)$. 


\section{Results and Discussion}

\section{Effect of activated brackish water irrigation on soil water content}

The water content of $0-100 \mathrm{~cm}$ soil under the irrigation of activated brackish water during the growth period is shown in Fig. 2. The soil water content fluctuated in the whole growth period, which was mainly related to irrigation, rainfall, evaporation and other factors (Tan et al., 2017). The soil water content under activated brackish water irrigation was significantly higher than that under brackish water control, while the soil water content under IB irrigation was slightly higher than MB. In 2018, the average soil water content under MB irrigation increased by $14.90 \%$ compared with control $\mathrm{B}$, and the average soil water content under IB irrigation increased by $28.55 \%$ compared with control B. In 2019, the average soil water content under MB irrigation increased by $13.07 \%$ compared with control $\mathrm{B}$, and the average soil water content under IB irrigation increased by $28.15 \%$ compared with control B. The experimental results of the two years were slightly different, but they were consistent with the results of Wang et al. (2021). The results indicate that activated brackish water irrigation con effectively improve the soil water content during the growth period of fragrant pear. This is mainly because the associated water molecular cluster and contact angle become smaller after the activation treatment of brackish water (Chibowski and Szcześ, 2018), and the water is easier to enter the small soil pores, which can store a large amount of water in the soil effective pores and reduce the evaporation loss (Shan et al., 2021). As a result, the soil water content of 0-100 cm under activated brackish water irrigation is higher as a whole.
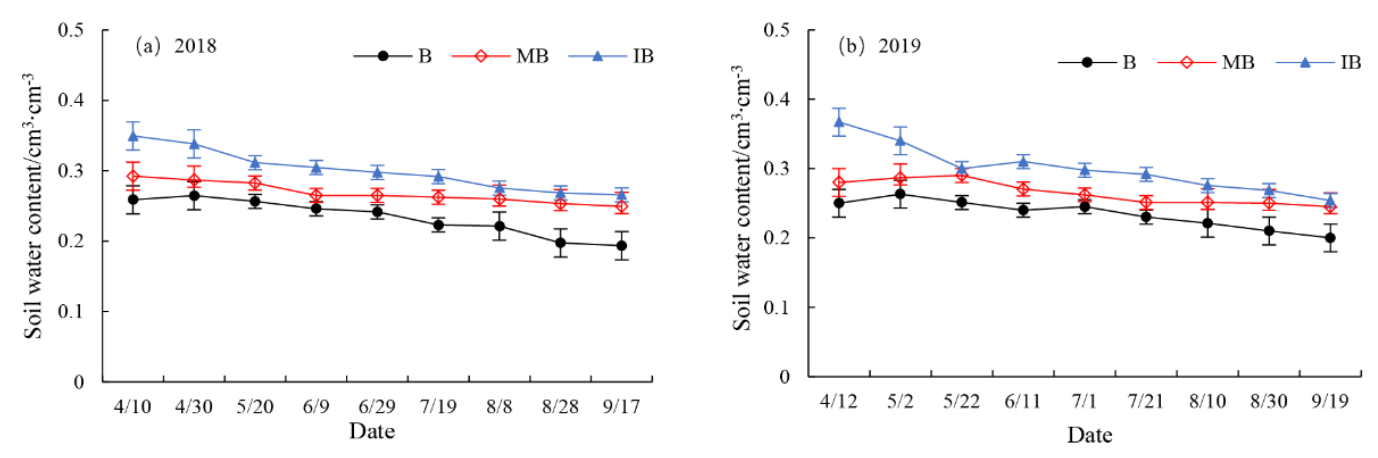

Figure 2. Soil water content of fragrant pear during growth period under activated brackish water irrigation. $B, M B$ and $I B$ represent brackish water, magnetized brackish water and ionized brackish water, respectively. The error bars represent standard deviations

\section{Effect of activated brackish water irrigation on new shoot length of fragrant pear trees}

New shoots and branches are the basic unit of flowering and fruiting of fragrant pear tree. The length of new shoots is directly related to the transmission efficiency of nutrients and fruit development of fragrant pear tree (Wu et al., 2012). Fig. 3 showed the change process of new shoot length of fragrant pear tree under activated brackish water irrigation at leaf spreading stage. During the leaf development period of fragrant pear, the length of new shoots and branches of each treatment increased with the advance of growth time. In 2018, the maximum shoot length of fragrant pear fruit trees irrigated with B, MB and IB was $43.55 \mathrm{~cm}, 51.33 \mathrm{~cm}$ and $64.80 \mathrm{~cm}$, which increased by $17.87 \%$ and $48.79 \%$ compared with control B. In 2019, the maximum shoot length of fragrant pear fruit trees irrigated 
with $\mathrm{B}, \mathrm{MB}$ and IB was $41.55 \mathrm{~cm}, 53.32 \mathrm{~cm}$ and $62.79 \mathrm{~cm}$, which increased by $28.33 \%$ and 51.12\% compared with control B. Wang et al. (2019a) showed that the shoot growth of grapes irrigated with magnetized brackish water increased by $25.56 \%$, and Wang et al. (2021) showed that the dry matter mass of wheat irrigated with ionized water increased by $29.7 \%$, which were consistent with this study. Therefore, the activated brackish water irrigation is beneficial to promote the growth of new shoots of fragrant pear fruit trees and effectively increase the biomass of fragrant pear fruit trees. On the one hand, the activated brackish water irrigation improves the soil water storage in the main root layer of fragrant pear trees and provides sufficient water for the growth of new shoots of fragrant pear trees (Zhao et al., 2021), on the other hand, the water quality performance of activated brackish water is improved (the reducing of surface tension (Liu and Cao, 2021) and the increase of dissolved oxygen and solubility (Wang et al., 2018)), salt activity is reduced ( $\mathrm{Bu}$ et al., 2010), and the carrying capacity of nutrient elements is improved (Liu et al., 2020), which provides sufficient nutrients for the growth of new shoots of fragrant pear fruit trees, resulting in faster growth of new shoots of fragrant pear trees.
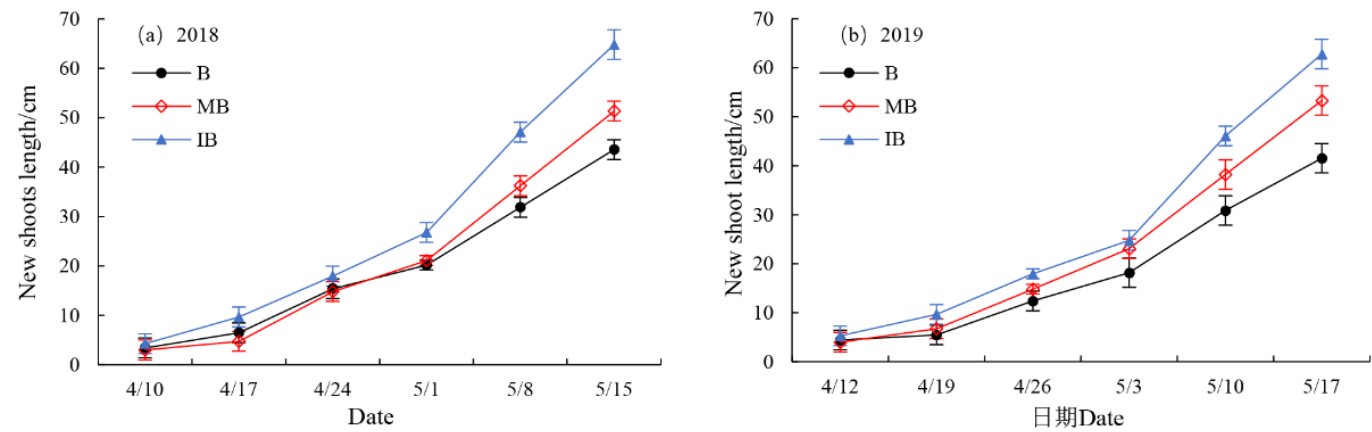

Figure 3. New shoot lengths of fragrant pear tree under activated brackish water irrigation. $B$, $M B$ and IB represent brackish water, magnetized brackish water and ionized brackish water, respectively. The error bars represent standard deviations

\section{Effect of activated brackish water irrigation on fruit shape of fragrant pear}

The fruit shape of fragrant pear is one of the important indicators that determine whether its commodity value is competitive in the high-end international pear market (Chen et al., 2020). As can be seen from Table 1, activated brackish water irrigation had significant effect on fruit shape of fragrant pear $(P<0.05)$. Compared with control B treatment, the longitudinal diameter of fragrant pear irrigated with MB and IB increased by $6.76 \%, 7.22 \%(2018)$ and $7.25 \%, 8.83 \%$ (2019), the transverse diameter decreased by $4.40 \%, 2.16 \%$ (2018) and $2.17 \%, 1.65 \%$ (2019), the fruit shape index increased by $11.68 \%, 9.58 \%(2018)$ and $9.62 \%, 10.66 \%$ (2019), and the volume of fragrant pear increased by $8.96 \%, 11.89 \%$ (2018) and $11.96 \%, 15.54 \%$ (2019). Li et al. (2011) showed that the fruit shape of fragrant pear with fruit shape index less than 1.12 was nearly round, and that greater than 1.29 was long oval. The fruit shape between 1.12 and 1.29 was oval, and the oval was better. The fruit shape of fragrant pear treated with control B was mostly nearly round, while the fruit shape of fragrant pear irrigated with MB and IB was mostly oval and upright. The results indicate that activated brackish water can not only effectively improve the volume of fragrant pear fruit, but also improve the fruit shape of 
fragrant pear to a certain extent, which may be due to the fact that activated brackish water irrigation could play a role similar to plant growth hormone to some extent (Boe and Salunkhe, 1963; Qiu et al., 2011), and can effectively regulate the improvement of fruit shape of fragrant pear.

Table 1. Fruit shape of fragrant pear irrigated with activated brackish water. $B, M B$ and $I B$ represent brackish water, magnetized brackish water and ionized brackish water, respectively

\begin{tabular}{c|c|c|c|c|c}
\hline Year & Treatment & $\begin{array}{c}\text { Longitudinal } \\
\text { diameter }(\mathbf{m m})\end{array}$ & $\begin{array}{c}\text { Transverse } \\
\text { diameter }(\mathbf{m m})\end{array}$ & $\begin{array}{c}\text { Fruit shape } \\
\text { index }\end{array}$ & $\begin{array}{c}\text { Fruit tree } \\
\text { volume }\left(\mathbf{c m}^{\mathbf{3}}\right)\end{array}$ \\
\hline \multirow{2}{*}{2018} & $\mathrm{~B}$ & $63.46 \mathrm{~b}$ & $56.55 \mathrm{a}$ & $1.12 \mathrm{~b}$ & $116.98 \mathrm{~b}$ \\
& $\mathrm{MB}$ & $67.75 \mathrm{a}$ & $54.06 \mathrm{c}$ & $1.25 \mathrm{a}$ & $127.45 \mathrm{a}$ \\
& $\mathrm{IB}$ & $68.04 \mathrm{a}$ & $55.33 \mathrm{~b}$ & $1.23 \mathrm{a}$ & $130.89 \mathrm{a}$ \\
\hline \multirow{2}{*}{2019} & $\mathrm{~B}$ & $64.53 \mathrm{~b}$ & $58.24 \mathrm{a}$ & $1.11 \mathrm{~b}$ & $123.57 \mathrm{c}$ \\
& $\mathrm{MB}$ & $69.21 \mathrm{a}$ & $56.98 \mathrm{~b}$ & $1.21 \mathrm{a}$ & $138.34 \mathrm{~b}$ \\
& $\mathrm{IB}$ & $70.23 \mathrm{a}$ & $57.28 \mathrm{~b}$ & $1.23 \mathrm{a}$ & $142.77 \mathrm{a}$ \\
\hline \multicolumn{2}{c|}{ Significance } & & & & \\
\multicolumn{2}{c|}{$\begin{array}{c}\text { Treatment } \\
\text { Year }\end{array}$} & $* *$ & $* * *$ & $* *$ & $* * *$ \\
\multicolumn{2}{c}{ Treatment $\times$ Year } & $* *$ & $* *$ & $*$ & $* * *$ \\
\hline
\end{tabular}

Different letters within a column indicate significant differences among all treatments at $\mathrm{P}<0.05$. *,

$* *$ And $* * *$ represent significant differences at the levels of $\mathrm{P}<0.05, \mathrm{P}<0.01$ and $\mathrm{P}<0.01$, respectively

\section{Effects of activated brackish water irrigation on yield and water use efficiency of fragrant pear}

Fig. 4 showed the yield and water use efficiency of fragrant pear under activated brackish water irrigation. The activated brackish water irrigation could significantly improve the yield and water use efficiency of fragrant pear $(P<0.05)$. Compared with control B treatment, the yield of fragrant pear irrigated with $\mathrm{MB}$ and IB increased by $11.20 \%, 12.47 \%$ (2018) and 22.22\%, 25.08\% (2019), and water use efficiency increased by $12.97 \%, 14.15 \%$ (2018) and $25.24 \%, 26.21 \%$ (2019). Zhang et al. (2020) showed that the yield of winter wheat irrigated with magnetized water increased by $8.99 \%$ and the water use efficiency increased by $5.07 \%$, and Zhu and Li (2020) found that the yield of single tomato irrigated with ionized water increased by $19.87 \%$ and the irrigation water use efficiency increased by $37.69 \%$, which were consistent with the results of this study. The results indicate that activated brackish water irrigation can effectively improve the yield and water use efficiency of fragrant pear. On the one hand, activated brackish water irrigation can improve the availability of soil water and nutrients (Li et al., 2020a), which is conducive to the absorption and utilization of the roots of fragrant pear fruit trees (Mostafa et al., 2016), on the other hand, activated brackish water improves the water molecular activity. It is beneficial to promote the absorption and utilization of light energy by fragrant pear leaves (Liu et al., 2019), promote the transformation of photosynthetic substances (Liu et al., 2016), and finally improve the yield and water use efficiency of fragrant pear.

\section{Effect of activated brackish water irrigation on quality of fragrant pear}

The quality grade of fragrant pear is determined by the single fruit weight, hardness, soluble solid content, total acid content and vitamin $\mathrm{C}$ content of fragrant pear. As can be seen from Table 2, activated brackish water irrigation had a significant effect on the quality of fragrant pear $(P<0.05)$. Under activated brackish water irrigation, the fruit 
surface of fragrant pear was smooth, the peel was fine, the stem was intact, and the fruit was yellow-green. The single fruit weight of fragrant pear irrigated with brackish water was less than $120 \mathrm{~g}$, which could only reach the standard of first-grade fragrant pear, while the single fruit weight of fragrant pear irrigated with activated brackish water was between $120 \mathrm{~g}$ and $160 \mathrm{~g}$, which reached the standard of super-grade fragrant pear. Compared with control B treatment, the single fruit weight of fragrant pear irrigated with MB and IB increased by 15.96\%, 19.07\% (2018) and 20.33\%, 22.62\% (2019), hardness decreased by $21.69 \%, 23.90 \%$ (2018) and 20.65\%, 21.61\% (2019), soluble solids increased by $4.41 \%, 4.25 \%$ (2018) and $8.48 \%, 8.64 \%$ (2019), total acid decreased by $13.01 \%, 12.33 \%$ (2018) and 16.78\%, 17.72\% (2019), and the content of vitamin C decreased slightly, but not significantly $(P>0.05)$. This result is consistent with the result of Jia et al. (2019) using magnetized water to irrigate Lingwu winter jujube. Thus, activated brackish water irrigation can effectively improve the fruit soluble solid content, reduce the total acid content and improve the taste of fragrant pear to a certain extent. This is mainly because activated brackish water irrigation can improve the utilization rate of light energy of fragrant pear fruit trees, affect the allocation of photosynthetic products (Cai et al., 2020), and then improve the sugar acid balance inside the fruit (Wei et al., 2020).
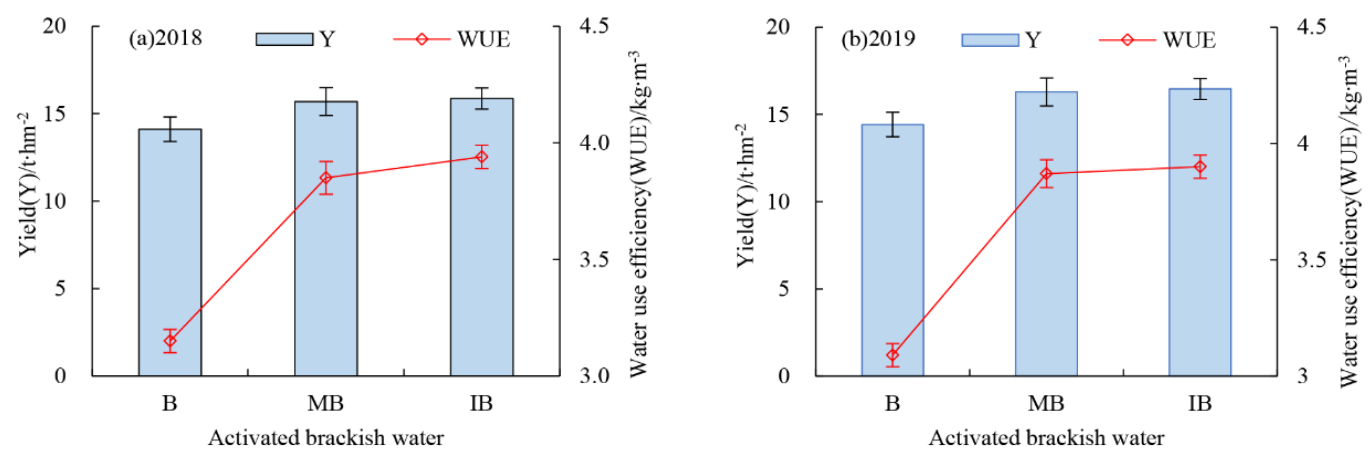

Figure 4. Yield and water use efficiency of fragrant pear under activated brackish water irrigation. B, MB and IB represent brackish water, magnetized brackish water and ionized brackish water, respectively. The error bars represent standard deviations

Table 2. The fruit quality index of fragrant pear under activated brackish water irrigation. $B$, $M B$ and IB represent brackish water, magnetized brackish water and ionized brackish water, respectively

\begin{tabular}{|c|c|c|c|c|c|c|}
\hline Year & Treatment & $\begin{array}{l}\text { Single fruit weight } \\
(\mathrm{g})\end{array}$ & $\begin{array}{c}\text { Solidity } \\
\left(\mathbf{k g} \cdot \mathbf{c m}^{-2}\right)\end{array}$ & $\begin{array}{c}\text { Soluble solids } \\
(\%)\end{array}$ & $\begin{array}{c}\text { Total acidity } \\
(\%)\end{array}$ & $\begin{array}{c}\text { Vitamin C } \\
\left(\mathrm{mg} \cdot \mathrm{kg}^{-1}\right)\end{array}$ \\
\hline \multirow{3}{*}{2018} & B & $113.76 b$ & $5.44 a$ & $12.24 \mathrm{~b}$ & $0.44 a$ & $6.10 \mathrm{a}$ \\
\hline & MB & $131.92 \mathrm{a}$ & $4.26 \mathrm{~b}$ & $12.78 \mathrm{a}$ & $0.38 b$ & $6.05 a$ \\
\hline & IB & $135.45 \mathrm{a}$ & $4.14 \mathrm{~b}$ & $12.76 \mathrm{a}$ & $0.38 \mathrm{~b}$ & $6.07 \mathrm{a}$ \\
\hline \multirow{3}{*}{2019} & $\mathrm{~B}$ & $118.43 b$ & $5.23 \mathrm{a}$ & $12.38 \mathrm{~b}$ & $0.43 a$ & $6.50 \mathrm{a}$ \\
\hline & MB & $142.51 \mathrm{a}$ & $4.15 b$ & $13.43 \mathrm{a}$ & $0.36 b$ & $6.42 \mathrm{a}$ \\
\hline & IB & $145.22 \mathrm{a}$ & $4.10 \mathrm{~b}$ & $13.45 \mathrm{a}$ & $0.35 \mathrm{~b}$ & $6.45 \mathrm{a}$ \\
\hline \multicolumn{7}{|c|}{ Significance } \\
\hline \multicolumn{2}{|c|}{ Treatment } & $* *$ & $* *$ & $* *$ & $* *$ & NS \\
\hline \multicolumn{2}{|c|}{ Year } & $*$ & $*$ & $* *$ & $*$ & NS \\
\hline \multicolumn{2}{|c|}{ Treatment $\times$ Year } & $* * *$ & $* *$ & $* * *$ & $* *$ & NS \\
\hline
\end{tabular}

Different letters within a column indicate significant differences among all treatments at $\mathrm{P}<0.05$. *, $* *$ And $* * *$ represent significant differences at the levels of $\mathrm{P}<0.05, \mathrm{P}<0.01$ and $\mathrm{P}<0.01$, respectively, and NS represents no significant difference $(\mathrm{P}>0.05)$ 


\section{Conclusions}

In this study, the effects of activated brackish water irrigation on the growth, fruit shape, yield, quality and water use efficiency of fragrant pear trees aged 15 years were studied through a two-year field irrigation experiments. The main conclusions are as follows:

(1) The activated brackish water irrigation can effectively improve the soil water content. During the growth period, the soil water content of the main root of fragrant pear fruit trees increases by $13.07 \%-28.15 \%$.

(2) The maximum new shoot length of fragrant pear fruit trees irrigated with activated brackish water increased by $17.87 \%-51.12 \%$, the fruit volume increased by $8.96 \%-15.54 \%$, and the fruit shape of fragrant pear tended to be oval.

(3) Activated brackish water irrigation can not only improve the yield and water use efficiency of fragrant pear, but also improve the soluble solid content, reduce the total acid content and improve the taste of fragrant pear.

Generally speaking, in arid areas where fresh water is scarce, using activated brackish water instead of brackish water to irrigate fragrant pear can obtain a higher yield and quality. However, the optimal amount of irrigation and fertilization of fragrant pear irrigated with activated brackish water need to be further studied.

Acknowledgements. This study was funded by the National Natural Science Foundation of China (41830754 and 52179042).

\section{REFERENCES}

[1] Abdel-Kader, H. H., El-Saady, W. A., Zaky, H. A. (2020): Effect of magnetized water and NPK fertilization treatments on growth and field performance of gladiolus. - Journal of Plant Production 11(7): 627-632.

[2] Al-Bayar, M. A., Mahmood, R. M., Saieed, A. Y. (2020): Magnetic treated water, reality and applications: A review. - Plant Archives 20(2): 732-737.

[3] Boe, A. A., Salunkhe, D. K. (1963): Effects of magnetic fields on tomato ripening. - Nature 199: 91-92.

[4] Bu, D. S., Feng, W. G., Cai, L. H., Zhou, L. (2010): Effects of magnetization water on desalinization in cotton farmland of under-film dripping irrigation in XinJiang Province. Transactions of the Chinese Society of Agricultural Engineering 26(3): 163-166. (in Chinese with English abstract).

[5] Cai, M. L., Li, Y. Y., Fan, J. (2020): Effects of magnetized water on growth, photosynthesis and nutrient uptake of cucumber seedlings under different soil moisture contents. Agricultural Research in the Arid Areas 38(5): 94-100. (in Chinese with English abstract).

[6] Chen, W., Jin, M., Ferré, T. P. A., Liu, Y., Xian, Y., Shan, T., Ping, X. (2018): Spatial distribution of soil moisture, soil salinity, and root density beneath a cotton field under mulched drip irrigation with brackish and fresh water. - Field Crops Research 215(4): 207221.

[7] Chen, J., Lü, J., He, Z., Zhang, F., Zhang, S., Zhang, H. (2020a): Investigations into the production of volatile compounds in Korla fragrant pears (Pyrus sinkiangensis Yu). - Food chemistry 302(3): 125337.

[8] Chen, W., Jin, M., Ferré, T. P. A., Liu, Y., Huang, J., Xian, Y. (2020b): Soil conditions affect cotton root distribution and cotton yield under mulched drip irrigation. - Field Crops Research 249: 107743. 
[9] Chibowski, E., Szcześ, A. (2018): Magnetic water treatment-A review of the latest approaches. - Chemosphere 203(2): 54-67.

[10] Hamza, J. N. (2019): Investigation on using magnetic water technology for leaching high saline-sodic soils. - Environmental monitoring and assessment 191(8): 1-11.

[11] Han, S., Yang, Y., Li, H., Yang, Y., Wang, J., Cao, J. (2019): Determination of crop water use and coefficient in drip-irrigated cotton fields in arid regions. - Field Crops Research 236(2): 85-95.

[12] Jia, H., Li, L., Cao, B. (2019): Effects of magnetized water irrigation on vegetative growth and fruit quality of lingwuchangzao. - Journal of Nuclear Agricultural Sciences 33(11): 2280-2286. (in Chinese with English abstract).

[13] Li, F., Wu, J., Hu, R., Ma, B. X. (2011): Quantitative analysis and classification of fruit shape in Korla fragrant pear. - Journal of Shihezi University (Natural Science) 29(04): 514517. (in Chinese with English abstract).

[14] Li, M., Du, Y., Zhang, F., Bai, Y., Fan, J., Zhang, J., Chen, S. (2019): Simulation of cotton growth and soil water content under film-mulched drip irrigation using modified CSMCROPGRO-cotton model. - Agricultural Water Management 218: 124-138.

[15] Li, J., Fan, J., Zhu, Z. M. (2020a): Effects of activated water irrigation on growth characteristics of soybean under drought stress. - Chinese Journal of Applied Ecology 31(11): 3711-3718. (in Chinese with English abstract).

[16] Li, N., Lin, H., Wang, T., Li, Y., Liu, Y., Chen, X., Hu, X. (2020b): Impact of climate change on cotton growth and yields in Xinjiang, China. - Field Crops Research 247(4): 107590 .

[17] Liang, J., Shi, W., He, Z., Pang, L., Zhang, Y. (2019): Effects of poly- $\gamma$-glutamic acid on water use efficiency, cotton yield, and fiber quality in the sandy soil of southern Xinjiang, China. - Agricultural Water Management 218: 48-59.

[18] Liu, X., Wang, H. T., Wang, Y. P., Ma, F. Y., Wang, L., Wan, X. (2016): Analysis of magnetic salinity water irrigation promoting growth and photosynthetic characteristics of Populus $\times$ euramericanna 'Neva'. - Transactions of the Chinese Society of Agricultural Engineering 32(1): 1-7. (in Chinese with English abstract).

[19] Liu, X., Zhu, H., Meng, S., Bi, S., Zhang, Y., Wang, H., Song, C., Ma, F. (2019): The effects of magnetic treatment of irrigation water on seedling growth, photosynthetic capacity and nutrient contents of Populus $\times$ euramericana 'Neva' under $\mathrm{NaCl}$ stress. - Acta Physiologiae Plantarum 41(1): 1-13.

[20] Liu, X., Wang, L., Wei, Y., Zhang, Z., Zhu, H., Kong, L., Meng, S., Song, C., Wang, H., Ma, F. (2020): Irrigation with magnetically treated saline water influences the growth and photosynthetic capability of Vitis vinifera L. seedlings. - Scientia Horticulturae 262: 109056.

[21] Liu, J., Cao, Y. (2021): Experimental study on the surface tension of magnetized water. International Communications in Heat and Mass Transfer 121: 105091.

[22] Maheshwari, B. L., Grewal, H. S. (2009): Magnetic treatment of irrigation water: Its effects on vegetable crop yield and water productivity. - Agricultural water management 96(8): 1229-1236.

[23] Mostafa, M. F. M., El-Boray, M. S. S., Shalan, A. M. N., Ghaffar, A. H. (2016): Effect of magnetized irrigation water levels and compost on vegetative growth, leaf mineral content and water use efficiency of Washington navel orange trees. - Journal of Plant Production 7(2): 249-255.

[24] Mu, Y., Zhao, G. Q., Zhao, Q. Q. (2019): Advances in the application of activated water irrigation. - Journal of Agricultural Resources and Environment 36(04): 403-411. (in Chinese with English abstract).

[25] Niu, Y., Chen, X., Zhou, W., Li, W., Zhao, S., Nasir, M., Dong, S., Zhang, S., Liao, K. (2019): Genetic relationship between the 'Korla fragrant pear' and local pear varieties in xinjiang based on floral organ characteristics. - Scientia Horticulturae 257: 108621. 
[26] Qiu, N., Tan, Y., Shen, X., Han, R., Lin, Y., Ma, Z. (2011): Biological effects of magnetized water on seed germination, seedling growth and physiological characteristics of wheat. - Plant Physiology Communications 47(8): 803-810.

[27] Shan, Y. Y., Li, X. J., Wang, Q. J., Ma, C. G., Zhang, J. H., Wei, K. (2021): Analysis of one-dimensional horizontal absorption characteristics and water movement parameters of magnetized brackish water. - Transactions of the Chinese Society for Agricultural Machinery 52(2): 266-274. (in Chinese with English abstract).

[28] Surendran, U., Sandeep, O., Joseph, E. J. (2016): The impacts of magnetic treatment of irrigation water on plant, water and soil characteristics. - Agricultural water management 178: 21-29.

[29] Tan, S., Wang, Q., Xu, D., Zhang, J., Shan, Y. (2017): Evaluating effects of four controlling methods in bare strips on soil temperature, water, and salt accumulation under filmmulched drip irrigation. - Field Crops Research 214: 350-358.

[30] Turker, M., Temirci, C., Battal, P., Erez, M. E. (2007): The effects of an artificial and static magnetic field on plant growth, chlorophyll and phytohormone levels in maize and sunflower plants. - Phyton Ann. Rei Bot 46: 271-284.

[31] Wang, Q. J., Zhang, J. H., Men, Q., Tan. S., Zhou, L. W., Liu, X. Y. (2016): Experiment on physical and chemical characteristics of activated brackish water by magnetization or ionization. - Transactions of the Chinese Society of Agricultural Engineering 32(10): 6066. (in Chinese with English abstract).

[32] Wang, Y., Wei, H., Li, Z. (2018): Effect of magnetic field on the physical properties of water. - Results in Physics 8: 262-267.

[33] Wang, L., Guo, J. Y., Bi, S. S., Zhang, Z. H., Wang, H. T., Liu, X. M., Zhu, H., Tang, J., Chen, S. Y., Cong, G. Z. (2019a): Effects of irrigation with magnetized saline water on Vitis vinifera growth and soil mineral nutrients. - Journal of Fruit Science 36(12): 16831692. (in Chinese with English abstract).

[34] Wang, Z., Wu, Q., Fan, B., Zheng, X., Zhang, J., Li, W., Guo, L. (2019b): Effects of mulching biodegradable films under drip irrigation on soil hydrothermal conditions and cotton (Gossypium hirsutum L.) yield. - Agricultural water management 213: 477-485.

[35] Wang, L. L., Wu, W. Y., Xiao, J., Huang, Q. N. (2020): The effects of spatial layout of drip irrigation belts on growth and water use efficiency of golden pear. - Journal of Irrigation and Drainage 39(5): 10-17. (in Chinese with English abstract).

[36] Wang, Y. H., Sun, H. W., Wei, C. H., Wang, L. (2021): Effects of activated water on growth and root activity of wheat. - ACTA Agriculturae Boreali-Sinica 36(1): 124-133. (in Chinese with English abstract).

[37] Wei, Y., Wang, L., Zhu, H. (2020): Effects of magnetized water irrigation on growth and photosynthetic characteristics of grape under nitrogen application. - Journal of Nuclear Agricultural Sciences 34(04): 849-859. (in Chinese with English abstract).

[38] Wu, Y., Wang, W., Huang, X. F., Ren, D. X., Su, L. Y., Liu, Z. H. (2012): Yield and root growth of mature Korla fragrant pear tree under deficit irrigation. - Transactions of the Chinese Society for Agricultural Machinery 43(09): 78-84. (in Chinese with English abstract).

[39] Yuan, C., Feng, S., Huo, Z., Ji, Q. (2019): Effects of deficit irrigation with saline water on soil water-salt distribution and water use efficiency of maize for seed production in arid Northwest China. - Agricultural water management 212: 424-432.

[40] Zhang, Y. Y., Song, N., Shan, Z. J., Liu, X. F., Ning, H. F., Wu, J. L., Chen, Z. F. (2020): Effects of magnetic treatment of irrigation water on yield and water use efficiency of winter wheat. - Journal of Irrigation and Drainage 39(6): 60-66. (in Chinese with English abstract).

[41] Zhao, G., Mu, Y., Wang, Y., Wang, L. (2021): Response of winter-wheat grain yield and water-use efficiency to irrigation with activated water on Guanzhong Plain in China. Irrigation Science 39(2): 263-276. 
[42] Zhou, B., Yang, L., Chen, X., Ye, S., Peng, Y., Liang, C. (2021): Effect of magnetic water irrigation on the improvement of salinized soil and cotton growth in Xinjiang. Agricultural Water Management 248: 106784.

[43] Zhu, M., Li, B. (2020): Effects of irrigation with de-electronic water on yield, quality and water use efficiency of tomato grown in greenhouse. - Water Saving Irrigation 11: 20-24. (in Chinese with English abstract). 